\title{
Lapurdum
}

LAPURDUM Euskal ikerketen aldizkaria | Revue d'études basques |

Revista de estudios vascos | Basque studies review

$8 \mid 2003$

Numéro VIII

\section{Baladen itzultze eta moldatze moduez}

\section{Patri Urkizu}

URL : http://journals.openedition.org/lapurdum/1176

DOI : 10.4000/lapurdum. 1176

ISSN : 1965-0655

Éditeur

IKER

Édition imprimée

Date de publication : 1 novembre 2003

Pagination : 479-500

ISBN : 9782867813436

ISSN : $1273-3830$

\section{Référence électronique}

Patri Urkizu, «Baladen itzultze eta moldatze moduez », Lapurdum [Linean], 8 | 2003, Sarean emana---an 01 juin 2009, kontsultatu 19 avril 2019. URL : http://journals.openedition.org/lapurdum/1176 ; DOI : 10.4000/lapurdum. 1176 


\section{Patri Urkizu}

UNED

\section{Baladen itzultze eta moldatze moduez}

Jakina da baladak etorkiz pertsona baten sorkuntzak direla, baina honen izena gehienetan urteen eta mendeen poderiopean galdu egiten da, anonimatoan erortzen da, eta berea bezala herriak hartzen duelarik tradiziozko bilakatzen da balada.

Orokorrean baladek eredu folkloriko unibertsalak erabiltzen dituzte lehen ekai gisara, lekuan lekuko bereizgarriak hartzen dituzten arren. Batzuetan ezaugarri historiko zehatzak mantentzen badituzte ere gehienetan partikulartasun hoiek galtzen joaten dira baratxetto egiantzekotasun nobeleskoa hartuz eta orokortasunean murgilduz.

Nolazpait esateko, balada nortasun propioaren eta beste herri hurbilen edo urrunen jenioen topagunea bilakatzen da. Horregatik saiatu izan dira zenbait ikerle lehen eredua edo arketipoa aurkitzen aldaerak heien artean konparatuz. Horixe egin zuen Lachmann-ek bere metodo ospetsuaz eta hari jarraiki izan diote Doncieux-ek frantses eremuan eta hala Gavelek nola Orpustanek euskal alorrean: azken bi hauetarik lehenak Berterretxen khantorea aztertuz 1924ean eta bigarrenak Atharratze Jauregian ikertuz 1999an, hobeto irakurrri eta konpreni ahal ditzagun.

Halere Daniel Devoto hispanistak ikerketa metodo zaharkituak kritikatzen eta metodo berriak proposatzen dituelarik, kontsideratzen du, adibidez, metodo geografikoak mapak eta mapak eginez, eta ehunka bertsio bata bestearen ondoan ezarriz hala nola arketipoa bilatzen saiatuz ez duela zentzu handirik lan horien emankortasuna eskasa delako, benetan interesgarria dena aldaeren funtzionamendua eta funtzionaltasuna aztertzea baita. Honek ematen baitio benetan argitasun berezia eta sakontasun gehiago ikerketari eta ez asmatzea sekula kantatuko ez zen arketipoa.

Beraz, Gavelek ematen digunean berak eraiki testua, hori inork inoiz kantatu ez zuen khantorea zen, - ez bazuen berak sortu eta gero kantatu-, baina dena dela balio digu bere azterketak, zeren ohar historiko, filologiko eta literario askorekin batera aldaera hauek nolakoak ziren agertzen baitigu.

Piarres Lafitte eta Louis Dassance-k menderdi bat geroago Khantu, Kanta, Khantore (1967) esku liburuttoan, - aurrerantzean KKK bezala aipa- 
tuko duguna -, Gavelek proposatua hartu zuten beste bi bertso erantsiz eta noski zenbait zuzenketarekin batera beste errata batzu burutu zituzten, kopia guztietan gertatzen den bezala. Hala, ahürkaz > ahürka, bestera > bestila, Büztanobi > Bustanobi, Büztanobira > Bustanobila, hirur > hiru, orhit $>$ orhoit,...

Jon Juaristik ematen digunean Flor de baladas vascas (1989) liburua, besteak beste Balada zaharrak, Euskal Herriko baladak, eta Europako guztiko baladak edo balada paneuropearrak aipatzen dizkigu eta zenbait paralelo aipatzen. Paraleloez aparte guk aldamenean ipiniko ditugu zenbait adibide ikusteko nola funtzionatzen duten itzultzaile eta moldatzaileek.

Lehenetarikoa Françoise Barrenquy-k egina 1809an eta Santiagoko Bidean gertatu mirariaren itzulpena da. Ezaguna den bezala XII. mendean hasi zirenean bidaia propagandak egiten, Calixto II-a Aita Saindua Jundane Jakobe Handiaren buruzko zenbait liburuxkaren egilea dugu, hauen artean $D e$ Miraculis Sancti Jacobi latinezkoaren idazlea, non V miraria geroago ezagutua izan den Urkatu piztuarena bezala. Latinezko testua frantsesera, gailegora, katalanera, gaztelaniara eta Europako beste hizkuntza gehienetara ere itzuli edo moldatu zen, euskaraz Jundane Jakoberen bizitza eta heriotza kontatzen duen pastoralean ere ageri dena.

Bertan kontatzen da nola Errioxan Santo Domingo de la Calzada herrian (non donde cantó la gallina después de asada, lelo errimaduna maiz darabilten) gertatu zen miraria. Bertsoak, kantak, ipuinak eta antzerkiak egin ziren mirari honen inguruan eta honela moldatu zuen Barrenquyk frantses testua:

Quand nous fûmes à saint Dominique Hélas! Mon Dieu, Nous entrâmes dedans l'Église

Pour prier Dieu:

Le miracle du pèlerin

Por notre adresse Avons oui le coq chanter Dont nous fûmes bien aise.
Saint Domingora nintzanian

Elas, jinko jauna,

Elizan barna sarthu nintzan,

Othoitze egitera.

Han ikusi nin mirakuilu

Pelegrier heltia,

Oilarra entzun khantatzen

Hareki oilo xuria.

Argi eta garbi dago euskaratzaileak ia zuzen-zuzen jarraikitzen diola Lorsque nous partîmes de France abestiari, zein Les Chansons des pélerins de Saint-Jacques liburuan aurki daitekeen, Frantziako Troyes-en plazaratua zen 1718an eta jada XVIL. mendeaz geroztik Frantzia osoan barreiatua.

Aldaerak eta eranskinak oso ttipiak dira, noski, besteak beste, oilo xuriaren eransketa. Iruditzen zitzaion, antza, itzultzaileari oilarrak behar zuela ere bere kidea. Pastoralegilearen antzez-oharrak ere honelaxe dio: Jaki pularda eta olaskua eta kantatzen has platin. 
Hel diezaiogun orain beste kanta bati.

Jesus Cid irakasleak esaten digunez, garbi dago Judu herratua balada ere konplainta frantses baten itzulpena dela. Baina euskaraz badira aldaera ezberdinak (Barbier, 1933, Azkue, T. IV, n' ${ }^{\circ} X X I$, Donostia, T. VII, n617, KKK 145. or, Satrustegi, 1967) non ikus daitezkeen itzultze modu ezberdinen funtzionamendua. Beha ditzagun:

Honela dio frantses orijinalaren 11. bertsoak:

\section{- Isaac Laquedem}

Pour nom me fut donné;

Né à Jérusalem,

Ville bien renommée,

Oui, c'est moi, mes enfants,

Qui suis le Juif errant.

Barbierrek eta Dufau-k emandako bertsioak orijinalaren 24 bertsoak ditu itzuliak eta 11. bertsoa honela itzulia:

-Izraelgo hirian izan niz deitua, Jerusaleme famos hirian sortua, Satisfa bedi beraz zien izpiritua, Jaunak, ni nuzie bai, Judu erratua.

Aita Donostiak, aldiz, Atharratzen 1927an bildu zazpi bertsotako kantan 11.a 3.a bilakatua da eta honela jasotzen du:
Bai, Isaak Lakeden
düzü ene izena, Jerüsalemen sorthia, herri hanitx aiphatia, Jesüs jaunak haitatia. Eta ni hanko semia, Bethi malerus nizana, mündian paregabia!

Beraz, ikus dezakegu koplari lapurtarra eta zuberotarrak aski molde ezberdinetan itzuli dutela orijinala, baina bada bertso bat non orijinaletik bereizteko biek hartu duten bide bera, alegia, erromesari hiritarrek ezkeintzen diotenean un pot de bière fraîche, biek zerbezaren ordez ardoa itzultzen dute, hobeto esateko, Barbierrek arnoa eta Bedekarrats Atharratzeko zapataginak ardu. 
Har dezagun beste balada bat, KKK-n Elhorri xuriaren azpian bezala izendatzen dena, adibidez. Damase Arbaud-ek probentzalez egindakoak bildu zituenean Chants populaires de la Provence liburuan (1862) Les Tres Capitanis bezala bataiatu zuen, George Doncieux-ek Celle qui fait la morte pour son honneur garder eta Henri Davenson-ek, La Belle qui fait la morte.

Davenson-ek dioskunez, hau martxa kanta bat da, alegia, soldaduen artean moldatua XVII. mendean eta Frantzia osoan zabaldua, bai Bretainian, bai Okzitanian, bai eta Euskal Herrian.

Ikus dezagun adibidez nola ageri den lehen bertsoa Lot-eko bertsioan Canteloube de Malaret ${ }^{1}$ batek bildua :

Dessous le rosier blanc la belle s'y promène

Blanch"comm" la neige, belle comme le jour.

Trois jeunes capitaines lui vont faire l'amour.

Azkuek kanta honen bi bertsio bildu zituen, halaber Aita Donostiak. Zavalak, aldiz, hamabi, baina Agosti Chahok bere eskuzkribu argitaragabean badu bertsio bat gure ustez zaharrena edo bederen testu frantsesa zuzenkien segitzen duena, eta honela hasten dena, hain zuzen:

Arrosa xuriaren artian anderia luak hartu,

Elhurra bezain xuririk, ekhia bezain ederrik,

Hirur kapitain zaudian khortez inganaturik. (ff. 158-165)

KKK-n ageri den bertsioa honakoa da:

Elorri xuriaren azpian anderea lokartu,

Arrosa bezain eder, elurra bezain xuririk,

Hiru kapitainek deramate gortez enganaturik.

Anderia, neskatxa, "la belle" frantsesez, probentzalez 'belo filho' garbitasunaren irudia bezala har daiteke noski, eta edergarri zenbaitekin konparatu ditu poetak: arrosa xuria, elorri xuria, elhurra, ekhia...

- Bitxia da nola Joseph de Canteloube-ren Anthologie des Chants Populaires Français groupés et présentés par Pays ou Provinces. Durand \& Cie, Paris 1951, Akademia frantsesak eta Arte Ederretakoak 1951an sarituan eta lau tomotan denaren Table des matières edo aurkibidean, ageri diren probintzia guztiak tartean "Le Béarn, La Gascogne eta La Corse" badaude baina ez Le Pays basque, euskal hamar kanta bertan sartu arren (T. I, 272, 274, 295, 296, 297, 298, 300, 345, 347, 349). 
Faire l'amour esamoldeak ez du esanahi, noski, ordain errezegi batez gaztelaniaz "hacer el amor" eta euskaraz "amodioa egin" oraingo gazteek diotenaren arabera, hacer la corte, khortea egin baizik. Aita Donostiak bere 191. zenbakian ordea, garbi dago ez duela konprenitu ongi edo berak edo edizioa prestatu duenak, zeren ematen duena gorkiaz engeyaturik den eta ez duen itzultzen.

Chahoren bertsioko bostgarren bertsoa desagertu egin da KKK-n, zeren agertzen baita soldadoaren nahiaren betetzearen adierazpena: Aspaldian desir zünina orai düzia gogatü.

Badu, gainera, halako parekotasun bat ixtorioak Jesukristorenakin, hau bezala hirugarren egunean pizten baita, - surrexit tertia die-. Anderea hila bezala jo ondoren pizten da, eta oihu egiten dio aitari, hilobia idek diezaion eskatuz, bere zergatia argitzen duelarik: Birjinitatea beiratu nahiz hila egona nüzü.

KKK-n auzapez eta apaiz bertso-biltzaileak, berdin dio, frantses orijinalean bezala hemen bukatu beharrean balada, beren moral ukituari jarraiki, bertso bat erantsi beharrean aurkitu dira, eta sari gisara neskatxari agintzen dio aitak jaun gazte aberats batekin ezkonduko duela. Benetan soberan dagoena, dudarik gabe.

Doncieux-ek balada hau eskandinabiarren artean ere aurkitu zuen, eta antza denez hemendik Bohemiako eslaboengana pasatu zen. Hala, bertsio txekiar batean neska moldabiarra da, eta hila bezala egonen da ere amorante turkiar batengandik ihes egitearren.

Juan Mari Lekuonak bere Oiartzungo kantutegia bertako herri memoriatik (1999) liburuan dioenez, Errenteriako ehiztari batzuek Etxalarren ikasi zuten aldaera bat eta Oiartzunen landatu, hau sei bertsotakoa delarik.

Bestalde Chahoren aldaeran eta KKK-n bigarren bertsoan ageri trozatï, trozaturik aditza, Lot-eko bertsioan ageri ez dena, eta etorkiz troussatik 'bildu', ('envolver'gaztelaniaz) letorkeenak pentsarazten digu aldaera gaskoin edo biarnesaren bitartez sartua izan zitekeela gurean. Interprete kantari ugari izan ditu frantses musikan, hala nola Mouloudji, Serge Kerval, JeanFrançois Dutertre eta euskal munduan Anje Duhalde.

$$
\text { 此涹 }
$$

Neska ontziratua-z mintza gaitezen orain.

Zavalak hamasei bertsio ezberdin ematen digun arren, denak Brodatzen ari nintzen... sailean sartzen dizkigu, zein den KKK-n ageri den titulua ere eta lehen bertsolerroaren hasiera bertsio batzuetan. Jon Kortazarrek, aldiz, Neska Ontziratua bezala izendatzen du Julio Caro Barojaren omenaldi baterako egin artikuluan. Doncieux-ek L'embarquement de la fille aux chansons, Claude Roy-k aldiz, La fille des sables, Ternuako bertsioetan Charmant matelot, eta bertsio katalanetan El Mariner bezala. Gaztelaniazko bertsio laburtuan, zeinek baduen beste bat luzeagoa sefardieraz, El Conde Arnaldos, bezala ezagutzen da. 
Neskaren bahiketa eta honek bere buruaz beste egitea oso zabaldua dago mendebaldeko literauretan eta badu antzekotasunik Hirur kapitainak gaiarekin. Bretoieraz ere ageri da guwerz batean, zeinek hiru aldaera dituen. Hemen kortsari ingelesak Bretainako kostara jaisten dira eta neska gazte bat bahitzen dute. Neskatxak bere ohorea salbatzearren kapitainari eskatzen dio zubitik pasiatzen utz dezan eta halako batean bere burua itsasora botatzen du. Bertsio batean arrain batek axalean mantentzen du eta itsasertzeraino darama.

Noski, bukaera honetan nabarmena da koplariak ixtorioaren happy end baten bila dabilela, eta Bibliako oroitzapenak dakarzkigula, alegia, Jonas eta Balearen ixtorioa.

Leit motiv delakoa garbi dago elkarrizketa honetan eta frantses bi bertso hauek direla :

\section{La chanson que vous dites la voudrois bien savoir. \\ - Entrez dedans ma barque et je vous l'apprendrai.}

Zein itsasoa iraganik Ternuan honela kantatzen den:

La chanson que vous chanter, j'aimerais de la savoir (bis)

J'aimerais de la savoir sur le bord de l'ille.

J'aimerais de la savoir sur le bord de l'eau.

Toujours près des vaiseaux, charmant matelot.

Eta horrelaxe bukatzen dute gainera bertso guztiek, charmant matelot, alegia, txo ederra. Dena den Neska Ontziratua bezala izendatuko dugun balada hau gurean lehen aldiz oraindik argitaratu gabe dagoen Chahoren kanta bilduman bi aldaeretan ageri da (ff.161-164). Batean lehen bertsoak honela dio:

Aldi batez ari nündüzün sala baxian brodatzen, Ezkutari bat entzun nizun galeriati khantatzen, Galeriati khantatzen eta kobla ederren emaiten.

Eta besteak beste honelako sarrera dauka, ezkutaria jada kapitan bilakatu delarik:

Aldixe batez nenguelarik sala baxian brodatzen,

Kapitain entzun dizut itxason gainen khantatzen, Itxason khantatzen eta kobla eijerrik emaiten.

Europako beste literaturetan ere ageri zaigu gaia esan bezala modu eta era ezberdinetan. Adibidez katalaneraz El Mariner bezala bataiaturiko kanta bertso hauekin hasten dena: 


\section{A la vora de la mar \\ $n$ 'hi ha una donzella \\ que brodava un mocador \\ que es per la reina...}

Frantsesez, Roy-ren La fille des sables bezala deitu bertsioan honelako sarrera dauka:

Dans la ville des sables

$Y$ a-t-une fille à marier.

Sur le bord de la mer

elle est là qui écoute

le marinier chanter.

Badu ere parekotasunik gaztelaniazko El Conde Arnaldos erromantze ospetsuak, zeinen bertsio anitzetarik batek dioen honelaxe bere bukaeran :

- Por tu vida el marinero

Respondióle el marinero

- Yo no digo mi canción digasme ora ese cantar.

tal respuesta le fue a dar:

sino a quien conmigo va.

Eta sefardiek badute beren errepertorioan italierazko aldaera zeinek kantinela eta guzti honela dioen:

La bella monta in nave

Kominsyya a navegar,

Laran, larin don dela,

Kominsyya a navegar.

Armstead, sefardien literaturan aditua denak dioen legez, italierazko mailegu horiek adierazten digute behin berriro, poesia tradizio honen multikulturalismoa, zein era berean izan zitekeen hala hispaniarra nola atzerritarra.

Eta, noski, euskal kantagintza ere ezen gelditu mendebaldeko kanta mugimendu hauetatik kanpo, baina itzultze eta moldatze berriz, modua berezia erabili, hala nola frantsesezko madarikazioa, Maudite soit l'épée et celui qui l'a forgée! dena honela ager baitaiteke: Maradika dakiola arotzari besua!, Maradika dakiola dendariari orratza! eta Deabru gaiztoak eraman deiela dendariari honen jostura! 
Itsasoko kantekin gabiltzanez har dezagun Zavalak jasotzen ez duen Ene muthilik ttipiena. Frantsesez La courte paille, ingelesez William Makepeace Thackerayk bermoldaturiko argot bertsioan Little Billee, portugesez ia kanta nazionala bihurtu den $\mathrm{A}$ Nau Caterineta. Badira noski Eskandinabia aldean eta Islandian beste bertsio zaharragoak.

Gaia, itsas marinelen artean egoera larri batzuetan gertatu izan ohi den antropofagia da. Ez dutenez besterik jateko itsasontzian eta zazpi urte daramatenez ezin portura arribatuz txoa, muthilik ttipiena jaten dute bertsio batzuetan saltsa minez edota saltsa zuriz besteetan. Frantsesezko bertsioaren tituluak ageri diguna da zotzen-zoria, edo zotz ttipiena suertatzen zaionari huraxe izanen dela jana.

Hona hizkuntza ezberdinetan nolako moldaketak eman dituen. Gaskoieraz honelaxe dio Dessus la ma titulutzat duena Jean-François Bladék egin bilduman:

... Quin de bous, bràbos camarados, Au cap dou mast boudrio mounta?

Lou mès joen dous camarados

Ditz: Capitani, i bau monta.

... - Besi lou castèt de moun pèro,

Lou pais oun ban abourda.

Besi ma moi a sa frinesto

A sa frinesto a se pintua.

Alegia, gazteena eskaintzen dela masta nagusiko puntaraino igotzeko eta handik ikusten duela bere aitaren gaztelua eta bere maitea leihoan orrazten ari dela. Portugesez beste modu honetara moldaturik dago:

- Sobe, sobe, marujinho,

Vê se vês terras de Espanha $\ldots$

Já vejo terras de Espanha

Mais enxergo três meninas,

Uma sentada a coser,

A mais formosa de todas àquele mastro real, as praias de Portugal.

arejas de Portugal! debaixo de um laranjal: outra na roca a fiar, está no melo chorar.

Makepeace Thackeray-k burutu zortzi bertsotako ingelesezko Little Billee bertsioan honelaxe dio zazpigarrenak txoak ama gaixoak erakutsitako dotrinako errezoak egin ondoren: 
So Billy went up to yhe main-top gallant mast, And down he felle on bended knee.

He scarse had come to the twelfth commandment When up he jumps. "There's land I see...

Nabarmena da zer ikusten duten txo ezberdinek masta gainera igotzen direnean. Herrialde bakoitzak batzuetan bere aldamenekoak baina baita urrungoak. Portugesak Espaina eta Portugal. Frantsesak Babilonia eta Barbaria. Ingelesak Jerusalem eta Madagascar. Laburrenetakoak diren euskal bertsioetan, Katalona, Tolona eta Angeleterra. Bada gainera aita Donostiak bildutako hiru aldaerez aparte (Hazparnen, Espil anderearen ahotik 1922an; Azkainen, Dominique Lacarreren ahotik 1923an; Zalgizen 1923an eta Larramendi Azkaingo marinelarenetik. 1922an) bat berezia Kardaberaztarrak Ondarroan jasoa 1935ean, eta honela dioena:

\section{Palogaineko, palogaineko palogaineko puntara! \\ An dago Karmen lutoz beterik almuedazala bordatzen.}

Bitxia da ikustea nola Mariena edo Mariana Karmen den bilakatu, eta galerian/leihoan josten ari da dioen bertsolerroa almuedazala bordatzen ageri dela, zeinek seguruena baduen zerikustekorik gaztelania zaharreko almozala hitzarekin. Honek agirian dagoenez arabean du etorkia, eta otoitzerako tapiza esan nahi du.

$$
* * *
$$

Komenta dezagun orain Oreina Bilakatu Neska, edo lehen bertsolerroaren hasieraren arabera Zavalak Ura ixuririk sorginen bidean bezala izendatzen duena. Lehen aldiz Lafittek argitaratu zuen 1965ean, eta honetaz mintzatu dira besteak beste, euskal alorrean, Txomin Peillen, Koldo Biguri eta Jon Juaristi.

Kontatzen digu Juaristik nola Lafittek eman zuen lehen aldiz 1965ean iturria adierazi gabe, "Atlanta-Pirene-etako sinheste zaharrak" artikulu barnean.

Nondik etor zitekeen euskal lehen bertsolerroa pentsatuz ohartu nintzen Martin Pénet-ek plazaratu Mémoire de la chanson. 1100 chansons du Moyen-Âge à 1919 (1998), hamasei garren mendeko kanten artean ageri dela hau, eta titulua La blanche biche edo M'envoient jeter de l'eau dela. Eta garbi dago Malicorne taldeak (Gabriel Yacoub, Marie Yacoub, Hugues de Courson et bestek) erabili duen bertsioa (1977) Davensonek eta Juaristik ematen diguten bertsioa dela gertuena euskal baladatik. Hona konparatuz bion lehen bertsoak: 
M'envoient jeter de l'eau dans le chemin des fées

Ils m'ont donné un don qui m'a toujours resté,

Je suis fille le jour et la nuit blanche biche,

Tous les jours les gens du château me pursuivent.

Ura ixuririk sorginen bidean,

Dohaina bildu dut Bazko arratsean,

Gauaz Maddi nüzü, egunaz oreina,

Etxeko zakurrek xerkatzen nutena.

Lotura nabarmena da. Beraz, frantsesez batipat La Blanche Biche bezala ezagutua badirudi Normandia eta Mendebaldekoa dela, zelten mundukoa, hain zuzen, eta badela suediar balada bat ere gai antzekoa ukitzen duena. Patrick Coirault frantses kanta biltzaileak laurogei bertsio aurkitu ditu.

Cidek garbi utzi zuen ez zuela ikustekorik batere Lanzarote y el ciervo del pie blanco erromantzearekin, eta frantses testuarekin lotu behar zela.

Garbi dago Juaristirentzat ez dela aztertu behar Peillenek bezala modu nahasi eta konparatismo antropologiko zaharkituan testua, horretarako bidea Lafittek berak ematen bazion ere.

Leesome Brand bezala ageri zaigu Child-en bilduman eta garbi dago honekin ere lotura baduela, hots, eskoziar baladekin, honela baitio:

Ye 'll take your arrow and your bow, And ye will hund the deer and roe,

Be sure ye touch not the white hynde,

For she is o the woman kinde.

Arkoa eta fletxa hartuko dituk, eta oreina eta basauntza ehizatuko. Baina kontuz, ez ezazu orein xuria uki, emazteen klasekoa da eta.

Hona ehizatu ondoren eta denak mahaian direla, zer dion Maddik bere anaia Jakesi (Marguerite eta Renaud bertsio frantsesean):

- Vous n'avez qu'à manger

Ma tête est dans le plat

Mon sang est répandu

Et sur les noirs charbons suis la première assise et mon couer aux chevilles, par toute la cuisine, mes pauvres os y grillent.

Euskaraturik honelaxe gelditu zen:

- Afal, afal, Jakes. Ni nuk hor lehena,

Ene haragiaz betherik dupina.

Ama sala zolan, nigarra begian,

Puinala sartu du bere bihotzean. 
Garbi dago metrikaren arabera frantsesez zortzi hiruko edo hamabi biko direnak euskaraz laburtu egin direla lau laukora. Lakonismoa edo trinkotasuna deitzen zitzaion honi. Bestalde, ageri da pertsonaia bat frantses bertsioan ageri ez dena eta eman behar duena halako tristuraren neurria, hots, tragediaz oharturik ere bihotzean puinala sartzen duen ama.

Erdi Aroko mundu tragiko, fantastiko eta basa honekin loturik dago ere beste balada bat, zeinaz hasten diren frantses kantu bilduma asko, alegia, Le Roi Renaud, euskaraz Errege Jan.

Pénet-ek XV. mendekotzat jotzen du, eta zabalduenetarikoa omen Frantziako lurraldeetan. Davenson-ek bere aldetik dioskunez, baliteke Ipar Herrietako folkloreari mailegaturik izatea, ezen Elveskud edo Sire Olav-en zati bat dirudien. Hemendik Faeroer uharteetara, Eskoziara eta azkenik Bretainara gwerz bat sortuz igaro zen, azken hau Comte Nann izenez ezaguna. Eta antza denez Breizh herrialdetik frantses eremura pasatu zen. Davenson musikologoaren ustez duen aidea Ave maris stella kantu gregorianoaren moldatze askea besterik ez da, zein era berean Bach-ek harmonizaturiko Erschienen ist der herrliche Tag koru luteranoaren etorkian dagoen.

Euskal bertsioak bi dira. Bat De la Villéhelio andereak bildua eta plazaratua Souvenir des Pyrénées liburuxkan (1869) Alargunsa titulupean zazpi bertsotan eta Ene ama, otoi, errazu bezala izendatua Zavalarenean. Bestea, hamaika bertsotan Charles Bordes-ek jasoa 1898an La Tradition au Pays Basque artikulu bilduman. Ohi bezala izena aldatua ere, baina ez hainbeste ikusiko baitugu lehen eta azken bertsoak konparatuz ereduari jarraikitzen diola zuzen zuzen:

Le roi Renaud de guerre revint

Portant ses tripes dans les mains;

Sa mère était sur le crêneau

Qui vit venir son fils Renaud.

Errege Jan, zaoriturik,

Jin izan da armadetarik,

Am andria baratu ziozu

Etxian alagerarik. 
Nahiko modu traketsean egina dela itzulpena esango genuke ez baita errespetatzen adibidez bertsoak beharko lukeen bertsolerroen kopurua, batzuetan bost baititu lauren ordez, eta errimarik gabeko bertsolerro anitz baitago. Dena den, honek berak adieraziko liguke ez dela jakintsuen emaitza, herriarena baizik. Hona, azken bertsoen konparaketa:

-Terre, ouvre-toi! Terre, fends-toi!

Quej'aille avec Renaud mon roi!

Terre s'ouvrit, terre fendit

Et ci fut la belle engloutie.

- Lur santia erdira bedi,

ni ere barnen sar nadin.

Lur santia zen erdiratu,

Ni ere barnen sartu,

Espus jaüna bexarkatu,

Jinko Jaüna dela laüdatu. (De la Villéhelio)

Lur saintia, zerr'adi,

Ni barnen bara ahal nadin!...

Lur saintia da zerratu,

Ni errege Janeki baratu. (Bordes)

Argi eta garbi dago, bada, nolako funtzionamendua ereduarekiko hartzen duen koplari moldatzaileak. De la Villéhelio-ren bertsioan, ixtorioaren in medias res sartzen da, zehazkiago esateko, frantses bertsioaren seigarren bertsoan elkarrizketa ama eta alabaren artean hasten denean. Bordesenean, aldiz, hasiera-hasieratik jarraikitzen dio ereduari. Baladen mundu zabalean frantses bertsioa La complainte du roi Renaud bezala ezagutzen badugu, gurean ez genuke aipatu behar, ene uste apalez, Ene ama, otoi, errazu, edota Alargunsa tituluaz, Errege Jan bezala baizik.

$$
\text { *决* }
$$

Azter dezagun oraindik beste balada laukote bat kapitulu hau amaitzeko. Lehena Barbersa Janamari da.

Bladé-k gaskoinez eman zuen honen bertsioa eta Gaston Guillaumie$\mathrm{k}$ frantsesez Gaskoinako kantak eta dantzak bildu zituenean. Titulu hau ezarri zioten biek Lou Capitani de Casteljalous, Le capitaine de Casteljaloux, eta Davenson-ek ere ematen digu aide eta guzti La belle barbière izenez, esanez Coirault-ek dozenerdi bat aldaera bederen aurkitu zituela.

Guillaumie-ren ustetan erlijio gerlen garaikoa dugu kanta, eta bertan La Rochelle, protestanteen hiri ospetsua eta Casteljaloux, Albreteko dukatuarenaren arteko harremanak aipatzen omen ziren. 
Ezagutzen dugun bertsioetarik euskarazkoa (Oihenart aldizkaria, 2000), da luzeena, hemezortzi bertso baititu. Pierre Duny-Pêtré doniandar eta Euskaltzaindiko urgazle denak bildua. Gaskoinez honelaxe amaitzen da kanta kapitainak barbersaz maitemindurik berekin eraman duela adierazteko:

Aquí coumo de La Rouchèlo,

Biro bigouza bigouza doundèno,

S'en bengouc a Casteljalous

Biro bigouza bigouza dondon.

Alegia, Casteljaloux utzi eta La Rochellera joan zela ile-apaintzailea. Gurean Donibane Garazitik Lukuzeko jauregira izan zen bidaia. Lukuzeko familia Agramontarrekin batera Ipar Euskal Herriko indartsuenetarikoa izan zen mende anitzez eta Izura eta Landibarre besteak beste, bereak ziren. Bidaia hamaseigarren bertsoan honela gelditu zitzaion koplariari:

Kapitainak hartu zuen Janamari zaldian, Lukuzen egin dukete bizi on jauregian. ****:

Bigarrena Andere Okina izango da. Lafittek hamahiru bertsotako kanta hau plazaratu zuenean 1978an, Bilintxen ehunurteburuko omenaldian eta "Amodiozko kantuak Lapurdin, Baxenabarren eta Ziberoan" artikuluan honela aurkeztu zuen Pierre Topet Etchahunen Maria Solt eta Kastero eman ondoren:

Horrek ez du erran nahi ez dela euskaraz aurkitzen ahal, kantu gizen gordinagorik. Egun egunean ahantzixeak dira. Lehen, bakar batzu baziren Frantziako kazernetan usatu kantore zikinetarik guti edo aski aldatuak. Ez dut uste behin ere publikatuak izan diren. Funtsean, ez zuten merezi ere, ene gustuko.

Ezagutuena zen Baxenabarreko xoko batzuetan hitz hauiekin haste zena: "Zer ari zira, amaso, hola beti guri so?". Kondatzen zuen nola atso baten baratzean eta haren leiho-pean bi neska-mutiko parekatzen ziren: bertsuetan ez zen poesia izpirik. Ez dut haren kopiarik atxiki. Halere, ez baita hemen umerik, etxenplu gisa, Ogi-egile andere baten kontrako bertsu batzu irakurriko dauzkitzuet, barkamendu galdeginez ozarkeri gatik.

XIX. mendeko kahier batetik hartua omen zuen. Pénet-en liburua arakatuz aurkitu dugu zein den honen iturria, eta hauxe da: XVIII. mendekoa, 
hots, 1720 ingurukoa den Nicolas Gallet-en hitzak, musika anonimoa eta titulua hauxe duena: La boulangère a des écus. 1875ean opera irrigarria hiru ekitalditan emana Henri Meilhac eta Ludovig Halevy-ren eskutik, eta haur kantak ere eragin dituena. Hona nola den hasiera frantsesez eta euskaraz:

La boulangère a des écus

Qui ne lui coûtent guère,

Oui, elle en a je les ai vus,

J'ai vu la boulangère

- D'où te viennent tous ces écus,

Charmante Boulangère?

- Ils me viennent d'un gros Crésus

Dont je fais bien l'affaire.

Guti gostarik bildurik,

Sosak baditu okinak,

Baditu, aitortu daizkit,

Ez du lotsarik kokinak.

- Diru hoik nundik dituzu,

Anderetan xarmantena?

- Meraren moltsa joritik,

Usu heldu baita huna.

Antza denez, frantsesezko Crésus aberatsa, euskaraz jaun mera dugu, hau soldado ergelak, jaunxkilak eta fraileak baino maiteago baitu. Halaber amorosen okin gisara aurkezten zaionari hobesten du mera.

$* * *$

Hirugarrena Hiru soldado gazte izango da. Honen ereduak, besteak ez bezala, egile ezaguna du, jaioturtea eta titulua ere bai, Gustave Nadaud-ek 1858an hitzak eta aideak sortu baitzituen Les trois hussards izenpean, eta frantses interpretari anitzen artean bada bat Hirigaray izenekoa (1932). Gustave Nadaud poeta eta konpositore frantsesa Roubaix-en jaio zen 1820an eta Parisen hil 1893an. Negozioak utzi eta poesiara eta musikara moldatu zuen bere burua, hainbat lanen artean Chansons (1849), Encore des chansons (1873) eta Nouvelles Chansons (1889) plazaratu zituen. Béranger ospetsuaren estilokoa da, eta kantez aparte operetak, komediak eta eleberriak sortu zituen. Hona nola hasten diren lehen bi bertsoak frantsesez eta hona ere zein egokiera ematen dion koplari euskaldunak: 
C'étaient trois hussards de la garde

Qui s'en revenaient en congé;

Ils chantaient de façon gaillarde

Et marchaient d'un air dégagé.

- Je vais revoir celle que j'aime

C'est Margoton, dit le premier.

- C'est Madelon, dit le deuxième.

- C'est Jeanneton, dit le dernier.

Hiru soldado gazte gerlan ibilirik,

Etxerat heldu ziren su-tokietarik,

Arin zuten gogoa, bihotza berorik,

Ahora dena kantu, ohi alegerarik.

- Bai, gure beha daude gure izarñoak,

Kattalin duk neurea, erran du lehenak.

- Madalen duk neurea, dio bigarrenak.

- Neurea Jana-Mari, aithor du azkenak.

Bertsoz bertso bederatziak itzuli edota moldatu egin ditu koplariak, bukaera oso tristea duen kanta, Errozu amattori goraintzi, adio!/Gerlan ari naizela erregerendako,/Ez naizela gerlatik nihoiz itzuliko.

Lehen aldiz KKK-n argitaratu zen dakigularik eta Argizagi ederra... aidean kanta daiteke. Jakina den bezala 1870ean Anton Abbadiaren Lore Jokoak gerra zela eta ez ziren ospatu, baina hurrengo urtean Saran eman ziren eta poema pila aurkeztu zen gerra gaitzat harturik, adibidez: Joanes Berjesen ondu Gerla, Jean Iribarnegarayk "Xetre hazpandarra" bezala ezagutuak Galde onari prest, Joanes Etcheto errejentak Soldado mobila, Harrietek 1870an soldadu, Piarres Ibarrartek Soldado ondoa...

Ikusten denez kasernetan bazuten kahier frantsesak kopiatzeko astia eta hauek euskaratzeko edota moldatzekoa ere denbora sobera. Margoton, Madelon, Jeanneton frantsesez, Kattalin, Maddalen eta Jana-Mari dira euskaraz bilakatu.

Eta azkenik Peru Gurea Londresen... 1985ean Cid eta Lakarra jaunek hobekien eta zehatzen ikertu balada. Lehenak nondik norakokoak aztertzen zituen, alegia, Hildebrand zaharraren fartsa, lehen aldiz Herbeheretan dokumentatzen denez geroztik nola dagoen hedatua ez soilik Europa guztian (Espainian, Portugalen, Frantzian, Ingalaterran, Dinamarkan, 
Serbian, Albanian, eta beste) baita Estatu Batuetan, Kanadan, Bahamasetan edo Cabo Verden, ingelesek, frantsesek edo portugesek eramana. Bigarrenak euskaraz agertutako aldaera guztien edizioa ematen, hala nola musika eta ohar ugari.

Gaztelaniaz lehenetariko agertzea Correas-en Vocabulario de refranes proverbiales, 1627, delakoan dago eta honela azaltzen da:

Mi marido fue a la mar, chirlosmirlos fue a buskar, para ni ke no tengo mal; echá i bevamos.

Finxióse mala i ke no podia sanar sino kon los chirlosmirlos de la mar, i persuadió al marido ke fuese por ellos para tener ella tiempo de admitir al kura, $i$ al mexor zenar $i$ bever el marido dio sobre ellos.

W.M.H. Humelen-ek neerlanderaz daukan artikulu interesgarri batean "Toneel op de kermis, van Bruegel tot Bredero" deituan kontatzen digu, nola ferietan eta hirietako plazetan baziren Rederijkers izeneko batzuek, erretorikariak alegia, erretorika talde batzuek zeinen partaideek beren eginkizunen artean zeukaten plazetan antzeztea. Hau dela eta biltzen ziren besta hauek, prozesioak, ihauterietako ikuskizunak eta beste antolatzeko gremio eta ofizio ezberdinetako langileak, hala nola, ofizial mekanikoak, dendariak eta pintoreak. Hauek sortu ikonografiatik ikus daiteke nolakoak ziren antzezkizun haiek XVI. mende erditsutikan XVIIeraino Flandes aldean. Pintore hauek dira, besteak beste: Pieter Brueghel, (-zeinen De kermis op het Dorp, edo Marlier-ek izendatzen duen eran Kermesse avec théâtre en plein air et procession, eman dugun sarrerako irudi gisan, ikus daitekeen Fartsaren gaia), Pieter Balten, Hans Bol, Pieter van der Borcht, Gillis Mostaert, Frans Hogenberg, Jacob Savery.

Cid-ek ematen digun bertsio gaskoinean, - antza denez Dardy delako batek aurkitua -, senarra itsasotik haratago dihoa Uous dé bécâdo ba cérca oilagor arraultzen bila, gaztelaniazkoan esaten bazen chirlos-mirlos (honen esanahia argitu gabe, ipuin asturiano batean lanpernaren antzeko zerbait bezala definitzen badira, ene ustez hitz-jokoa da chirlo-rekin, edo chirlarekin zitekeen bezala, beraz esanahi lizuna estaliko) euskarazkoetan zirkun bedarrak, zirin belarrak, senda-belarrak bilatzea emaztearentzat joaten da senarra.

Hau mendebaldeko ereduan ematen da eta modu berezi batean ageri zaigu sorkuntza eta moldaketa; baina Duny-Pétré-k bildutakoan, - bi dendari lapurtarrengandik ikasia omen-, eta lehen aldiz 1983an argitaratuan, garbi dago frantses ereduari jarraikitzen diola zuzen-zuzen.

Bretaina iparraldeko eta Québec-eko bertsioetan honela dio kantak: 
Mon mari est à Montpellier,

Chercher de l'eau pour ma santé,

Pour la santé de ma maison.

Kyrie eleison.

Mon mari est allé à Paris;

Il n'est pas paré d'en revenir.

Kyrie, christi.

Il n'est pas paré d'en revenir

A sa maison

Kyrie eleison.

Senarra dizit Montpellier-en

Ene sendatzeko urketa,

Ez baitzaut sekulan itzultzen,

Kyrie, kyrie,

Ez baitzaut sekulan itzultzen

A la mezon

Kyrie, eleison.

Garbi dago iturria zein den noski, nonbait Euskal Herria Québec eta Bretaina artean gelditzen baita, baina baita ere koplari itzultzailemoldatzailearen jolasteko gogoa, ezen kasu honetan esaldi hutsa dena desio lizun erdi estali gisa ageri zaigu. Baina azkena, ezin bestela, nonbait, senarrak fraide maltzurra eta emazte kaskarina saskitik atereaz makil ukaldika ongixko jipoitzen ditu, baina morroiarekin egindako apostua galtzen.

Amaitzeko kapitulu hau esan dezagun ikusi ditugun batez ere Iparraldeko zenbait kanta eta baladetan garbi dagoela eredu okzitano eta frantsesekiko zorra, baina era berean itzultzaile-moldatzaileak bere jenio apurra erabili duela eta sormen ikutu batez erantsi diola, orijinalitatea ezarriz bere hizkuntzaren doinu bereziari. 


\section{Bibliografia}

ARBAUD, D, 1862, Chants populaires de la Provence. Makaire. Aix.

AREJITA, A. et al., 1995, Mendebaldeko Euskal Baladak. Antologia. Labairu. BBK, Bilbao.

ARMISTEAD, S.G., "Canciones italianizantes entre los sefardíes de Oriente", Homenaje a Julio Caro Baroja. CSIC, Madrid, 101-109 or.

AZKUE, R.M., 1918, Cancionero popular vasco. 2 vols. Reed. La Gran Enciclopedia Vasca, Bilbao 1968.

- $\quad$-, 1947, Euskalerriaren Iakintza (Literatura popular del País Vasco).

T. IV. Espasa Calpe. Madrid.

BARBIER, J. "Nehor", \& DUFAU, C., 1933, Recueil de Chansons Basques. Gure Herria. Bayonne.

BIGURI, K., "El tema del cambio de sexo en la literatura vasca de tradición oral", Memoriae L. Mitxelena magistri sacrum. I. Anuario del Seminario de Filología Julio de Urquijo, 553-570 or.

BLADÉ, J.F. (ed.), 1882 , Poésies populaires de La Gascogne. 3 vols. G.P. Maisonneuve \& Larose, Paris.

BORDES, X., 1899, "La musique populaire des Basques", La tradition au Pays Basque, Paris, 297-361. Reed. Elkar, Donostia.1982.

-, 1890, Douze chansons amoureuses du Pays Basque-Français. Rouart, Lerolle \& Cie. Paris.

BRAGA, Th., 1906, Romanceiro General Portuguez. Lisboa.

BUTLER, G.R., 1995, Histoire et traditions orales des Franco-Acadiens de Terre-Neuve. Septentrion. Québec.

CANTELoUBE, J., 1951, Anthologie des Chants Populaires Français groupés et présentées par Pays ou Provinces. 4 vols. Durand et Cie. Paris.

CHILD, J. F., 1882, The english und scottish populars balladas. Boston.

CID, J.A., 1985, "Peru Gurea (EKZ, 115), der Scwank vom alten Hildebrand, y sus paralelos románicos (As. Th., 1360C), Anuario del Seminario de Filología Julio de Urquijo, 289-355 or. 
-, 2000, "Romancero hispánico y balada vasca”, Antonio Zavalaren ohoretan. Deustuko Unibertsitatea. Bilbo, 69-100.

COIRAULT, P., 1996, Répertoire des chansons françaises de tradition orale. Ouvrage révisé et complété, par George Delarue, Yvette Peclore et Simone Wallon. BNF. Paris.

DAVENSON, H. (ed.), 1982, Le livre des chansons ou Introduction à la chanson populaire française. Ed. de la Baconnière, Neuf châtel.

DEVOTO, D., 1955, "Sobre el estudio folklórico del Romancero español. Proposiciones para un método de estudio de la transmisión tradicional", Bulletin Hispanique, Bordeaux, 233-291 or.

DIAZ ROIG, M. (ed.), 1999, El romancero viejo. Cátedra, Létras Hispánicas. Madrid.

DONCIEUX, G., 1904, Le romancéro populaire de la France. E. Bouillon. Paris.

DONOSTIA, P. J. A., 1921, Euskel eres sorta. Unión Musical Española. Madrid.

-, 1994, Cancionero Vasco. J. Riezu (ed.), IV T., Eusko Ikaskuntza, Donostia.

DUNY-PETRE, p., 1983, "Montpelier-ko sendagailuak", Maiatz, 3, 60-61. or.

-, 2000, "Kapitaina eta barbersa janamari", Oihenart, Donostia.

ECHEVERRIA, P., 1971, Cancionero de los peregrinos de Santiago. Centro de estudios jacobeos. Santiago de Compostela.

ENTWISTLE, W. J., 1939, European Balladry. Oxford.

GAVEL, H., 1924, "Un chant historique du Pays Basque. Bereterretxen khantoria", Bulletin de la Société des Sciences, Lettres, Arts, et d'Études Régionales de Bayonne, 1-36 or.

GERICKE, Ph.O., 1989, "Formulismo situacional y contaminación en el romancero tradicional", El Romancero. Tradición y pervivencia a fines del siglo $X X$. Fundación Machado y Universidad de Cádiz. Cádiz, 65-71or.

GUILLAUMIE, G., 1945, Chansons et danses de la Gascogne. Ed. Delmas. Bordeaux.

HUMELEN, W.M.H., 2003, "Tonnel op de kermis, van Bruegel tot Bredero".Internet. www.dibnl.org/tekst/humm... 
JUARISTI, J., 1986, "El cantar de Beotibar, ¿ un romance noticiero vasco ?”, Anuario del Seminario de Filología Julio de Urquijo, Donostia, 845856 or.

-, 1987, "La balada vasca de la muchacha cierva", Anuario del Seminario de Filología Julio de Urquijo, 917-926 or.

-, 1989, Flor de baladas vascas. Visor. Madrid.

KORTAZAR, J., 1980, "Frantziako Kortekoa", Euskeraren Iker Atalak, 1, Labayru, 99-128 or.

-, 1986, "Neska ontziratua baladaren inguruan", Julio Caro Barojari omenaldia. RIEV, 891-905 or.

-, 2002, "La balada vasca", Literatura vasca. Ostoa,

Donostia, $70-74$ or.

LAFITTE, P., \& DASSANCE, L., 1967, Kantu, kanta, khantore. Bayonne.

LAFITTE, P., 1981, "Amodiozko kantuak Lapurdin, Baxenabarren eta Ziberon", Homenaje a Don Odon de Apraiz. Odon de Apraiz-i Omenaldia. Vitoria-Gazteiz, 199-214 or.

LEKUONA, J.-M., 1989, "La lírica popular vasca en el siglo XVIII", Congreso de Literatura (Hacia la literatura vasca), Castalia, Madrid, 495-525 or.

-, 1999, Oiartzungo kantutegia bertako herri memoriatik. Mugarri. Oiartzun.

MARISCAL de RHETT, B,, 1985, La muerte ocultada. Madrid.

MILA Y FONTANALS, M., 1895, Opúsculos literarios. T. Sexto de sus Obras Completas. Barcelona.

ORPUSTAN, J.-B., 1989, "Trois poèmes basques du XVIII siècle (1766) sur la vallée d'Ossés", Hommage au Musée Basque. Bayonne, 531-573 or.

-, 1999, "Lire et comprendre les textes poétiques de tradition orale: l'exemple de la chanson souletine Atharratze jauregian", Lapurdum IV, Bayonne, 57-81 or.

PENET, M., 1998, Mémoire de la Chanson. 1100 chansons du Moyen Âge à 1919. Omnibus. Paris.

ROLLAND, Eugène, 1967, Recueil des chansons populaires. Ed. Maisonnave-Larousse. Paris.

ROY, Cl., 1997, Trésor de la poésie populaire française. Anthologie. Plon. Paris. 
SATRUSTEGI, J.-M., 1967, Luzaide ko kantiak. Auspoa 65, Tolosa.

URKIZU, P. (ed.), 1991, Lapurdi, Baxanabarre eta Zuberoako bertso eta kantak. I. Anonimoak. II, 1545-1900, Etor, Donostia.

- $\quad$ - (ed. argitaragabea), Agosti Chaho eta Georges Lacomberen euskal bertso eta kanta bilduma.

VILLEHELIO, $\mathbf{M}^{\text {me }}$ de la, 1869, Souvenir des Pyrénées. Reed. J.A. Donostia, "Souvenir des Pyrénées. Recuerdo de los Pirineos. 12 canciones escogidas y anotadas por $\mathrm{M}^{\mathrm{me}}$ de la Villéhelio", Boletín de la Real Sociedad Vascongada de los Amigos del País, 1954, 309-337.

ZAVALA, A., 1996, Auspoaren auspoa. 2 vols. (Itzaldiak/conferencias). Sendoa, Oiartzun.

-, 1998, Euskal Erromantzeak. Romancero vasco. Auspoa, Oiartzun. 